\title{
La ALEgoría DE LA II RePÚblica Española en el Guernica de Picasso
}

\author{
The Allegory of the Second Spanish \\ Republic in Picasso's Guernica
}

NÉSTOR MOREnTE y Martín

Recibido: 05/06/2017 Evaluado: 18/10/2017 Aprobado: 04/01/2018

Resumen: En 1937 Pablo Picasso fue el seleccionado por el Gobierno de la República para que fuese la referencia artística del Pabellón Español en la Exposición Internacional de París. El tema a desarrollar tenía que ser la denuncia de la guerra civil española. El trabajo de Picasso, inspirado en la tragedia de Guernica, dará como resultado sin duda la obra más universal del siglo xx. Como jamás hizo una interpretación del cuadro, suscitó desde entonces que los historiadores hiciesen multitud de hipótesis. Una de ellas apunta a la personificación de la República en la figura femenina que porta el quinqué.

Palabras clave: Picasso, Guernica, alegoría, República, exposición.

Abstract: In 1937, Pablo Picasso was chosen by the Republican Government to be the artistic representative in the Spanish pavilion at the International Exhibition in Paris. The subject of the work was to be a denunciation of the Spanish Civil War. Picasso took his inspiration from the Guernica Tragedy, and the result was what is undoubtedly one of the most universally renowned paintings of the 20th century. As the artist never offered an interpretation of the painting, historians have since made an enormous variety of hypotheses. One of them suggests that the female figure carrying an oil lamp is the personification of the Republic. 
Keywords: Picasso, Guernica, allegory, Spanish Republic, International Exposition.

$\mathrm{E}$ 25 de mayo de 1937, se inauguró en París el último gran evento cultural a nivel internacional más relevante de los años treinta, la Exposition Internationale des «Arts et des Techniquesappliqués à la Vie moderne». El encuentro -con una masiva participación de naciones sin precedentes- estuvo marcado en gran medida por la Guerra Civil, que amenazaba con que el Gobierno legítimo de la República Española fuera sustituido por una dictadura militar de ideología fascista encabezada por el general Franco, quien había encabezado un golpe de Estado en la tarde del 17 de julio de 1936.

La Exposición Internacional de París fue el claro reflejo del futuro político que le esperaba a Europa, lo que se manifestaba en los pabellones de la Alemania (Nacionalsocialista) gobernada por Adolf Hitler, que en ese momento estaba apoyando el golpe de Estado contra la República Española, y el pabellón de la Unión de Repúblicas Socialistas Soviéticas (URSS). Ambos pabellones, casualmente situados uno enfrente del otro, exhibieron un planteamiento exacto en cuanto al gusto arquitectónico que debía de regir el futuro de sus naciones, con un claro referente y la mirada puesta en el clasicismo de la Antigüedad. Sin embargo, la simbología era más bien distinta, pues mientras el pabellón alemán exhibía el águila con la esvástica, símbolo del Partido Nazi, el soviético mostraba la Alegoría de la revolución proletaria, escultura colosal de Vera Mujina, en la que una mujer y un hombre exteriorizaban el emblema de la URSS empuñando la hoz y el martillo.

Saludando al pabellón nazi con otra escultura colosal se encontraba el de la Italia (fascista) de Benito Mussolini, con El genio del fascismo de Giorgio Gori. Este genio que ya no es alado ni porta la antorcha de la libertad como el de la Plaza de la Bastilla de París -aunque si su desnudez- se exponía sobre un caballo haciendo el saludo fascista dirigido hacia Alemania con cierta sumisión. El art déco en la este tipo de escultura así como el neoclasicismo arquitectónico, serán en esta exposición los referentes de vanguardia. Mientras tanto, el pabellón de la República Española optó por una estructura racionalista a cargo de los arquitectos Josep Lluís Sert y Luis Lacasa. En su interior se exhibían obras pertenecientes a múltiples estilos, prueba de la libertad artística del Gobierno republicano que no hizo gala de ninguno de ellos de forma oficial, convirtiéndose el Guernica en el ejemplo más destacado de esta cuestión. ${ }^{1}$ (fig. 1).

En enero de 1937, el Gobierno de la República tenía su sede oficial en la ciudad de Valencia, la amenaza rebelde había obligado a trasladar la capital y con ella cientos de artistas e intelectuales ante el peligro que corrían sus vidas.

1. Josefina Alix Trueba: Pabellón Español Exposición Internacional de París 1937, Centro de Arte Reina Sofía, Madrid, 1987. 


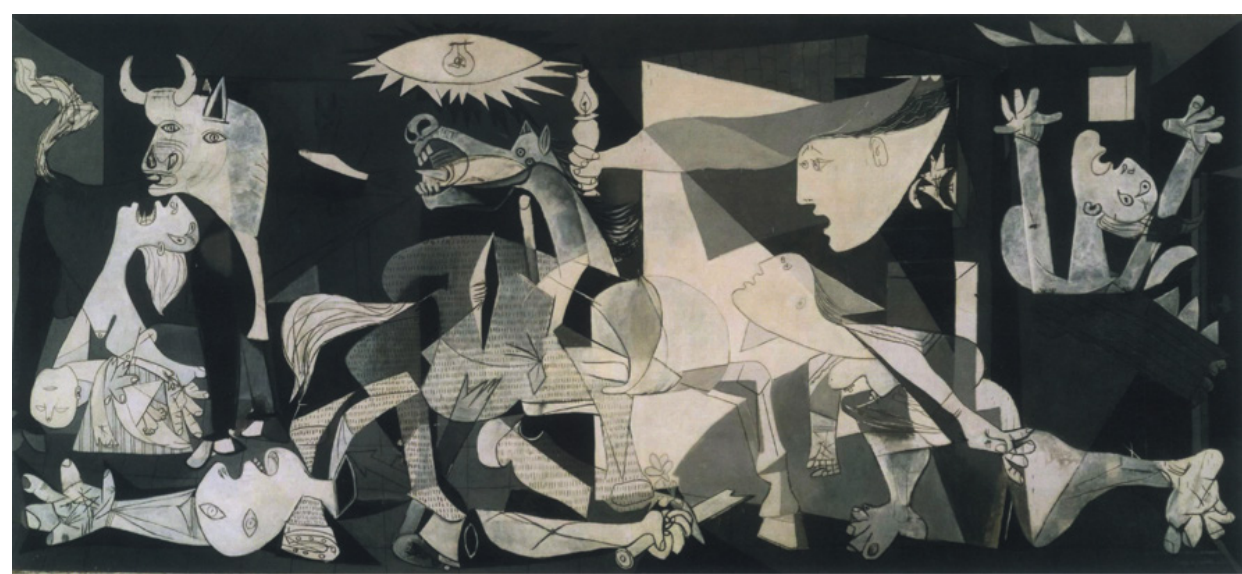

Fig. 1. Pablo Picasso. Guernica. 1937. Museo Nacional Centro de Arte Reina Sofía, Madrid

Valencia comenzaba ese año con la «Cabalgata del Niño» que aprovechó para denunciar en una multitudinaria manifestación el golpe de Estado contra el Gobierno legítimo. El 24 de enero, se inauguró el Congreso de las Juventudes Socialistas Unificadas (JSU), en el que participaron Dolores Ibárruri y Santiago Carrillo como ponentes. El evento se celebró en el Salón de Sesiones del Ayuntamiento de Valencia, lugar donde también se desarrolló, meses más tarde, el II Congreso Internacional de Escritores para la Defensa de la Cultura y donde el Gobierno decidió ubicar provisionalmente la sede del Parlamento español hasta su posterior traslado la Lonja de la Seda.

El año 1937 fue sin duda el de la esperanza para la República Española, el año decisivo en su lucha contra el fascismo, el año que regiría el destino de la nación. El Gobierno, aunque en estado de guerra, intentó continuar con la máxima normalidad el desarrollo de los eventos, convencidos -al menos entonces- de que el golpe no llegaría a triunfar. Así pues, se continuó con las sesiones parlamentarias y el desarrollo político, también en las artes, como lo demuestra la participación en la Exposición Internacional de París como una nación más, aunque denunciando la situación de la guerra. O el II Congreso de Escritores y otras exhibiciones, como la Exposición Nacional de Obras Públicas inaugurada el 11 de junio. ${ }^{2}$

El 17 de mayo, el ministro de Hacienda y miembro del Partido Socialista (PSOE) Juan Negrín, fue nombrado presidente del Gobierno. Poco después se emitió desde la ciudad de Castellón, la moneda más icónica, sin lugar a dudas, de la II República Española, la conocida como «rubia» o «peseta de Negrín», con valor de una peseta y que marcó su peculiaridad por ser la primera y hasta el momento única moneda en la historia de España en acuñarse en latón. En

2. vV. AA.: València, capital cultural de la República [1936-1937], Manuel Aznar Soler, Valencia, 2007, pp. 21-69. 
esta medida monetaria se reflejan principalmente dos cuestiones; por un lado la debilidad económica del Gobierno a causa de la guerra, al sustituir la peseta de plata de 1933 por la de latón, pero por otro el mensaje de continuidad y legitimidad del régimen republicano.

En 1937 Valencia, además de ser la sede oficial del Gobierno, era la capital cultural de la República. Uno de los artistas valencianos que en ese momento más destacaban por su arte cartelista y gestión sobre el patrimonio artístico fue Josep Renau, nombrado en 1936 Director General de Bellas Artes en un momento de extrema delicadeza y decisiones como el traslado de parte de las obras del Museo del Prado de Madrid a esta ciudad del levante para su mejor protección y salvaguarda. También era el director de la revista artística Nueva Cultura que había fundado en 1935 en defensa de la cultura popular y ontra el fascismo, en un claro ambiente prebélico. ${ }^{3}$

Fue el 27 de abril de 1936, cuando el entonces presidente del Gobierno, Santiago Casares Quiroga, confirmó la presencia de la República Española en la Exposición Internacional de París. Los fines que en ese momento se pensaron para el pabellón español eran principalmente turísticos, cuestión que tuvo que desecharse tras el inicio de la Guerra Civil, quedando la organización así como todo el programa en manos de Josep Renau. El artista valenciano desempeñó en esta cuestión un papel determinante, pues tuvo que rehacer prácticamente todo el enfoque para que el pabellón español pasase a ser, de cara al Mundo, el escaparate y denuncia de la guerra de España.

Aunque Pablo Picasso no había participado de forma activa con la República Española - pues vivía en París desde hacía casi tres décadas- Josep Renau, con la aprobación del Gobierno, pensó en él para que fuese la referencia del pabellón. Renau fue quien negoció con Picasso para que pintase la principal obra española de la Exposición Internacional. En enero de 1937, viajó a París para entrevistarse con él junto a Luis Lacasa -uno de los arquitectos del pabellón- y los escritores Max Aub, Juan Larrea y José Bergamín. Sin la actuación del pintor valenciano Josep Renau para que Picasso participase de este evento como la referencia internacional española, el Guernica jamás se hubiese realizado. ${ }^{4}$

Picasso aceptó sin dudar un instante la proposición que le hizo Renau en nombre del Gobierno de la República Española, pero lo cierto es que el pintor malagueño ya estaba informado sobre este asunto, pues justo un mes antes, en diciembre de 1936, Renau ya se había entrevistado a título personal con él para trasladarle la idea de que fuese su obra la referencia del pabellón español. Esto se evidencia en la misma visita de enero de 1937, pues Picasso, en el momento de recibir el encargo a título oficial, ya estaba elaborando los dos aguafuertes

3. Nueva Cultura: revista cultural fundada y editada en València por Josep Renau en 1935. Su último número se publicó en octubre de 1937. Biblioteca Valenciana Nicolau Primitiu, Valencia.

4. Genoveva Tusell: El Guernica recobrado. Picasso, el franquismo y la llegada de la obra a España, Cátedra, Madrid, 2017. 
que tituló Sueño y mentira de Franco, precedente de lo que sería, cuatro meses más tarde, el Guernica.

Un total de dieciocho escenas divididas en dos planchas de nueve viñetas cada una, componen la obra Sueño y mentira de Franco que Picasso diseñó sin guardar ninguna relación entre ellas, pues el fin de esta creación - de la que se llegaron a estampar un total de mil ejemplares- era venderlas por viñetas individuales para recaudar fondos destinados a la causa republicana. El 8 de enero de 1937, Picasso publicó las nueve primeras pertenecientes a la primera plancha. En la tercera escena de esta tirada, Picasso muestra a Franco con una piqueta en acción de destruir una alegoría de la República. El pintor seleccionó el símbolo de la Nación para anunciar que la libertad de España estaba en peligro. Este recurso lo volverá a emplear más tarde para el Guernica (fig. 2).
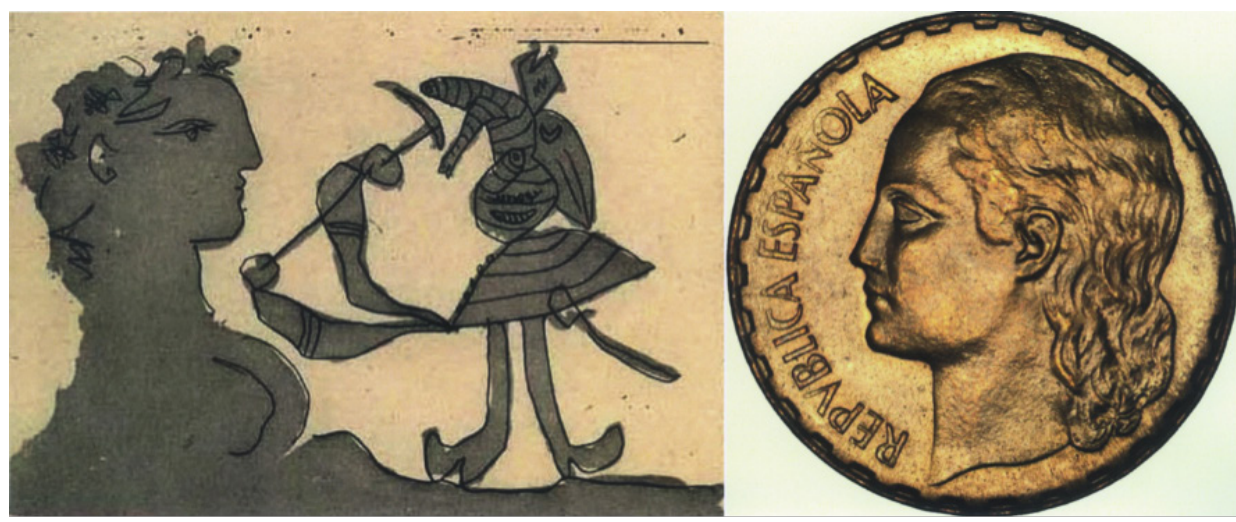

Fig. 2. Alegoría de la II República española en la viñeta Sueño y mentira de Franco y en la moneda de una peseta, 1937

Picasso, de forma paralela al encargo del Guernica, aceptó también -a petición de Josep Renau al Gobierno de la República - la dirección del Museo Nacional del Prado y, aunque no llegó a tomar posesión del mismo por la peligrosidad de la Guerra Civil, fue sin duda un cargo que desde la distancia llevó con dignidad, gratitud y orgullo, pues desde su adolescencia admirada las obras que allí se exponían y que tanto influyeron en su pintura como las de El Greco, Velázquez o Goya. La conexión de Picasso con Renau durante el periodo de la guerra será muy cercana y con un objetivo en común: el pabellón de la República Española de la Exposición Internacional de París.

Aunque desde diciembre de 1936, Picasso era conocedor del encargo para el pabellón español y del tema que debía desarrollar -denunciar el golpe de estado militar que había envuelto a España en una guerra civil-, no encontraba con total claridad la forma compositiva con la que desenvolverlo. De ahí que su obra previa al Guernica, Sueño y mentira de Franco, fuese en cierta manera una oportunidad de experimentar diferentes perspectivas para componer la 
pintura posterior así como la reacción que podría causar entre la población. El 26 de abril, a un mes de la inauguración de la Exposición Internacional de París, Picasso aún no tenía claro qué iba a presentar, pero el trágico suceso que ocurrió aquel día sería la fuente de inspiración para que terminara desarrollando la obra artística más relevante a nivel internacional del siglo xx, el Guernica. ${ }^{5}$

Ese mismo día, la localidad vasca de Guernica, leal al Gobierno legítimo de la República, fue arrasada sin más por la aviación nazi -que sin duda dirigió por su novedad militar el destino de la guerra-, la Legión Cóndor, apoyada además por la Aviación Legionaria del fascismo italiano. Este ataque genocida y fuera de toda batalla de guerra, atentando directamente y sin piedad contra la población civil en la que perecieron casi dos mil personas, dio la vuelta al mundo a través de la prensa internacional. Cinco días después, el 1 de mayo, Día Internacional del Trabajo, las calles de París se volcaron en una histórica manifestación para denunciar el ataque de Guernica. El pintor Pablo Picasso se encontraba entre los manifestantes. ${ }^{6}$

En la tarde de ese mismo día, Picasso, inspirado por la tragedia, comenzó a dibujar los primeros bocetos de la obra y ocho días más tarde tenía clara la composición del cuadro disponiéndose a pintarlo. En base a los bocetos preparatorios que hizo para el Guernica, se observa la variación de la mayor parte de las figuras que aparecen en la obra definitiva, pero hay una que reflejó en sus apuntes desde el primer instante y por su inalterable modificación, es claro y notorio que la tuvo en mente incluso antes de componer estos bocetos, una figura que sin lugar a dudas debía aparecer en el cuadro y como una de las más relevantes sino la más, según se entienda la interpretación de la obra.

Se trata de la figura femenina que asoma su cabeza por una ventana dejando ver su desnudez a través de sus senos. El rostro de perfil -más parecido a una silueta- asoma a la escena para presenciar lo que está sucediendo. Bajo la perspectiva surrealista, extiende su desproporcionado brazo derecho con el que sostiene un utensilio que emite luz. En el primer boceto parece una lámpara de luz eléctrica, en el segundo decide que sea luz de fuego - similar a una vela $o$ antorcha- aunque definitivamente se decida por ponerle sobre la mano un quinqué. El contorno del perfil de esta figura femenina evoca el de la alegoría de la República Francesa que diseñó Jean Carlú para el cartel oficial de la Exposición Internacional y que en ese momento ya se exhibía por las calles de París (fig. 3).

Los bocetos preparatorios para el Guernica, son fundamentales para el correcto estudio de la obra definitiva así como para acercarnos lo máximo posible a la realidad en lo que respecta a la idea inicial que tuvo Picasso para realizar este cuadro, así como a las posibles influencias artísticas en las que se

5. Ignacio Fontes De Garnica: 1937: el crimen fue en Guernica. Análisis de una mentira, Akal, Madrid, 2014.

6. Juan Larrea: Guernica: Pablo Picasso, Edicusa, Barcelona, 1977. 


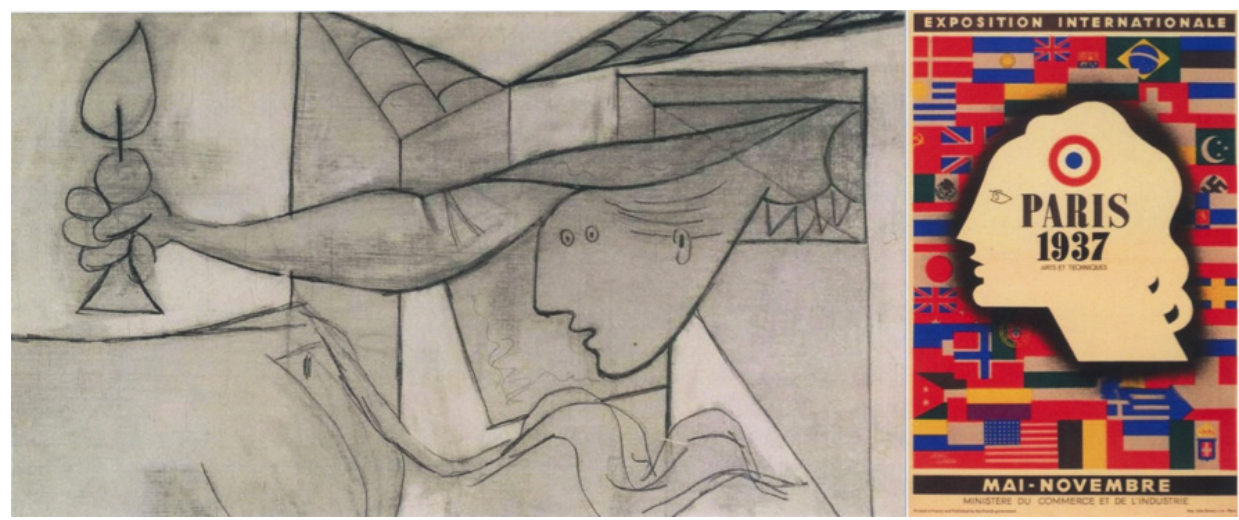

Fig. 3. Comparativa entre un boceto para el Guernica de Picasso y el cartel de la Exposición Internacional de París diseñado por Jean Carlú, 1937

pudo inspirar. De ahí, la importancia de la evolución que hace desde el inicio de este elemento que porta la alegoría femenina sobre su mano derecha, pues nos indica que no es una pieza más sin importancia, sino que lleva implícito un significado relevante y que decidió desde el primer boceto que fuese el motivo central del cuadro.

A esto hay que añadir que los bocetos nos aportan más información para hacer justicia a la importancia de esta antorcha que ocupa el centro de la composición. Se trata del sol, que ilumina a través de una bombilla eléctrica, elemento que Picasso no planificó en ninguno de sus bocetos, más aún, ni tan siquiera lo tenía pensado ya en plena realización de la obra, pues de los ocho estados del proceso pictórico con el que se conoce al Guernica, hasta el tercero de ellos no aparece para nada este elemento, su lugar lo ocupaba más bien la extensión del brazo del combatiente caído que en su último suspiro cierra el puño en alto para dar su último saludo a la República. En el tercer estado preparatorio del cuadro, es cuando Picasso decide cambiar la composición eliminando el brazo del combatiente caído sustituyéndolo por la figura del sol, pero tampoco con la forma elíptica y con bombilla eléctrica como en la obra definitiva sino circular, al modo clásico de representar a esta estrella.

La francesa Dora Maar, compañera sentimental de Picasso, era también pintora y escultora además de fotógrafa, lo que hizo que documentase todo el proceso de realización del cuadro en sus diferentes estados pictóricos. En lo que respecta a esta cuestión, son varias las opciones que las distintas publicaciones ofrecen a la investigación sin ponerse de acuerdo. En unos estudios se presentan como tres las etapas del proceso del Guernica, en otros en seis o incluso en siete. Lo cierto es que no se puede saber la cantidad de etapas en las que trabajó Picasso para esta obra, pero lo que sí se sabe con certeza, son aquellas con las que él decidió plantear su obra cara a la historia.

Esta cuestión también se la debemos a su estrecha amistad con el pintor valenciano Josep Renau, a quien envió desde París las fotografías del proceso 
pictórico del Guernica realizadas por Dora Maar, para que las publicase en exclusiva Nueva Cultura. Y así fue, en el número 4-5 de junio-julio de 1937, la revista cultural de Renau sacaba a la luz por primera vez en España los estados pictóricos del Guernica decididos por el propio Picasso en un total de ocho. Por otro lado, nada más finalizar la obra, que llegó con diez días de retraso al la exposición, Picasso invitó a cenar en su domicilio de París al embajador español Luís Araquistáin -que había colocado la primera piedra del pabellón español- y a Max Aub, agregado cultural de la Embajada de España, ambos miembros del PSOE. A pesar de que el pintor donó su obra a la República Española como un regalo para los españoles, el escritor Max Aubfue el encargado por el Gobierno para pagarle, al menos, los gastos de la producción, acción que años más tarde sería fundamental para poder reclamar el Guernica para España (fig. 4).
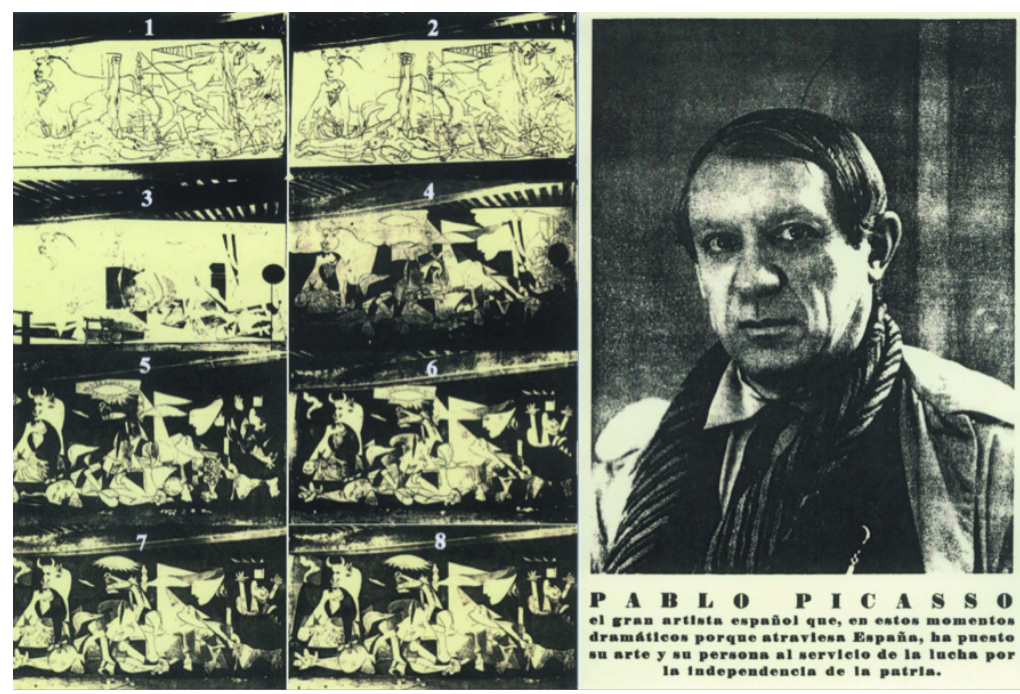

Fig. 4. Los ocho estados pictóricos del Guernica y fotografía de Pablo Picasso, publicado en la revista Nueva Cultura, 1937

Nada más concluir Picasso el Guernica y antes de su traslado al pabellón español, el 28 de mayo de 1937, Max Aub escribió al embajador Araquistáin para reunirse con el pintor:

\section{Excmo. Sr. Don Luis Araquistáin}

\section{Querido Don Luis:}

Le he esperado a usted hasta el mediodía, pero me dice Berdejo que tardará Ud. todavía en regresar del quai d'Orsay. Así, le pongo estas líneas precipitadamente, pues, como vinimos ayer, tomo el tren a las dos de la tarde para Bruselas.

Esta mañana llegué a un acuerdo con Picasso. A pesar de la resistencia de nuestro amigo a aceptar subvención alguna de la Embajada por la realización 
del Guernica, ya que hace donación de este cuadro a la República española, he insistido reiteradamente en transmitirle el deseo del Gobierno de reembolsarle, al menos, los gastos en que ha incurrido en su obra. He podido convencerle, y de esta suerte le he extendido un cheque por valor de 150.000 francos franceses, por los que me ha firmado el correspondiente recibo. Aunque esta suma tiene, más bien, un carácter simbólico, dado el valor inapreciable del lienzo en cuestión, representa, no obstante, prácticamente una adquisición del mismo por parte de la República. Estimo que esta fórmula era la más conveniente para reivindicar el derecho de propiedad del citado cuadro.

A mi vuelta de Bruselas, el lunes próximo, le entregaré a usted personalmente el precipitado recibo, que mientras tanto he depositado en la caja fuerte de la Embajada. Picasso desea que visitemos su taller de la rue des Grands-Augustins, para cenar después con él. Hasta pronto, suyo MAX AUB

En lo que respecta a las fuentes artísticas de las que Picasso pudo tomar referencia para pintar el Guernica, son muchas las conjeturas que se han hecho desde 1937. Sin duda, para escenificar el desastre de la guerra civil española - que era el tema oficial que tenía que desarrollar para París, aunque se inspiró posteriormenteen la tragedia ocurrida en Guernica- recurrió a varias fuentes artísticas. Dos obras son prácticamente seguras, pues era admirador ya desde su juventud de estos artistas. En primer lugar, la Alegoría de la Guerra de Peter Paul Rubens de 1637. Y en segundo lugar, el cuadro El 2 de Mayo de 1808 en Madrid de Francisco de Goya, realizado en 1814. Esta última, teniendo en cuenta la fecha en que Picasso comenzó a preparar los bocetos del Guernica, estuvo sin lugar a dudas en su pensamiento. ${ }^{8}$

En la trayectoria artística de Picasso, se observa esta admiración que tuvo por otras obras del pasado, como Las Meninas de Velázquez, que incluso trasladó a su propio estilo pictórico. Pero no sirva este ejemplo para compararlo con la obra excepcional del Guernica, en vista de que no se debe de confundir el hecho de trasladar una obra concreta a otro estilo diferente, que tomar como referencia obras pasadas para hacer con la misma temática una totalmente diferente, ex novo. La confusión entre trasladar y tomar referencias respecto de un trabajo artístico, es un asunto que también ha afectado al Guernica de Picasso, interpretándose en muchas ocasiones su obra como un traslado de otras, apuntando como la más común la Alegoría de la Guerra de Rubens (fig. 5).

Esto se contempla incluso en uno de los análisis más autorizados y reconocidos en España sobre esta obra, realizado por el profesor Santiago Sebastián López y que publicó en el libro: El Guernica y otras obras de Picasso: Contextos iconográficos, del Departamento de Historia del Arte de la Universidad de Murcia en el año 1984. En lo que atañe a la figura femenina y que Picasso pintó mostrando un quinqué a modo de antorcha, Sebastián la atribuye a la diosa Venus:

7. Carta de Max Aub al embajador español de París, 1937. http://cort.as/-C2Jd

8. Gijs Van Hensbergen: Guernica: la historia de un icono del siglo XX, Debate, Madrid, 2005. 


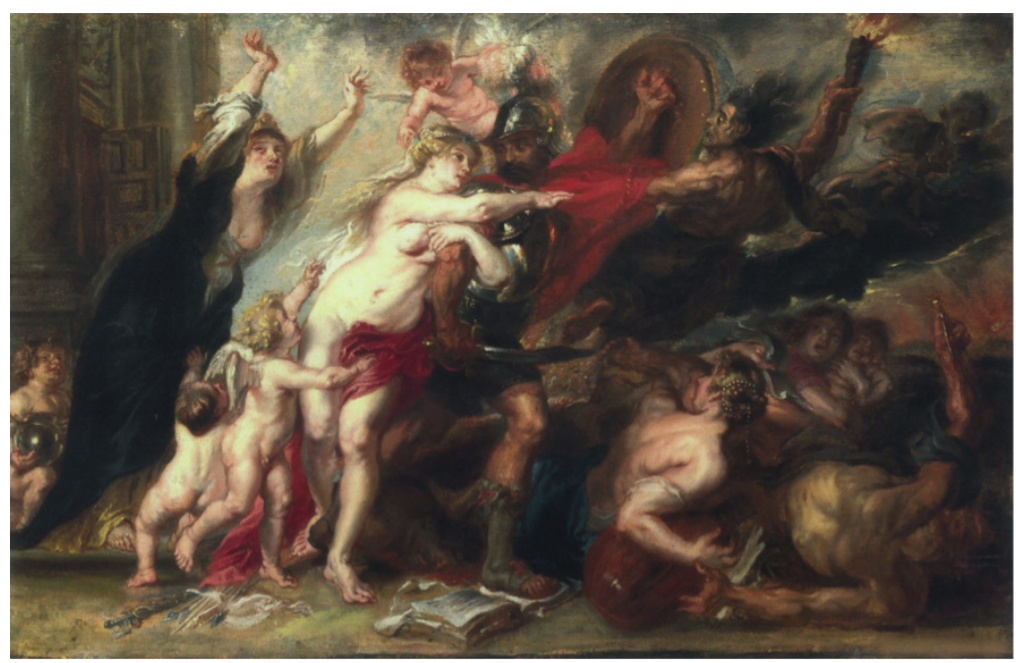

Fig. 5. Peter Paul Rubens. Alegoría de la guerra. 1637. Palacio Pitti, Florencia

Ella ahora, en esta lectura iconográfica, cumple la función de la Gran Madre, que al unirse al daimon taurino hará posible la creación gracias a la fuerza genésica de este. La conjunción de los principios - masculino y femenino- tiene un acento dramático, ya que se ha producido el caos por causa de la discordia y el odio, como señalan las escenas patéticas del artista muerto, de la maternidad y de la figura desesperada con los brazos levantados; ante esta perversión del orden cósmico, la mujer dispuesta en diagonal, evocación de las Furias, increpa a Helios para que restaure la Justicia. El conjunto está dominado por el mal, principio al que los pitagóricos dieron el nombre de lo «indefinido» y de lo «tenebroso», ello explica que la oscuridad y la falta de color sea la nota dominante en razón de su poder simbólico.

Lo novedoso de la iconografía de esta Venus picassiana es el que aparezca presentando con decisión un quinqué; tan extraña figura es una metamorfosis surrealista, ya que esta mentalidad dejó profunda huella en el artista. La iconografía renacentista representó a Venus llevando una antorcha en la mano ya dentro de los contextos nupciales[...] La Guerra ha engendrado la destrucción de la Humanidad, y lo más grave no solo la destrucción del orden cósmico, sino especialmente la destrucción de la Belleza, a la que se alude aquí por medio de Venus. En ese momento dramático ella presenta una luz, la diosa quiere manifestar que sobre el caos humano está la perennidad del Arte, es decir, de la Belleza como un orden estético superior preservado por los dioses. La luz de Venus da brillo y fulgor, que son dos de las características de la definición tradicional de la Belleza y que nos remiten al símbolo de la luz-divinidad, emanada aquí por Helios (126), ente solar por excelencia. ${ }^{9}$

9. Santiago Sebastián: El «Guernica» y otras obras de Picasso: contextos iconográficos, Departamento de Historia del Arte-Universidad de Murcia, Murcia, 1984, pp. 113-114. 
Relacionando el análisis de Sebastián en comparativa entre la Alegoría de la Guerra de Rubens y el Guernica, en primer lugar atribuye la figura de la mujer que Picasso ubica en la parte derecha en disposición diagonal, con las Furias que increpan a Helios para que restaure la justicia. Rubens, sin embargo, representa a las Furias desde la figura de Alecto animando al dios de la guerra a cumplir su cometido. A esta contradicción de relacionar a las Furias como intercesoras de la paz cuando son las diosas de la venganza, hay que tener en cuenta que Picasso no tiene pensado incluir esta figura hasta su boceto definitivo del 9 de mayo y en este, la mujer dirige su mirada hacia quien porta el quinqué, no hacia el sol, elemento que el autor no tuvo pensado pintar hasta prácticamente el tercer estado pictórico. Este hecho descarta toda posibilidad de que esta figura evoque a las Furias y por ende a todo un entramado mitológico, al menos el pintor no pensó en ello.

En segundo lugar, relaciona la figura femenina que porta el quinqué en la mano con la diosa Venus, apoyándose en el elemento de la antorcha como atributo de esta diosa. Cierto es que en algunas representaciones -aunque muy concretas- se incluye, pero tanto histórica como iconográficamente no es un atributo que caracterice a la diosa del amor, de hecho Rubens en su obra no relaciona a Venus con la antorcha, que sin embargo sí coloca en la mano de Alecto. Esto evidencia también que el quinqué del Guernica no guarda ninguna relación con la antorcha de la obra de Rubens (fig. 6).

Para analizar la figura femenina que Picasso incluyó en el Guernica mostrando su desnudez y portando un quinqué, hay que recurrir en primer lugar al significado que adoptó la antorcha durante la Ilustración y Revolución francesa, partiendo de dos alegorías que la muestran como principal atributo y

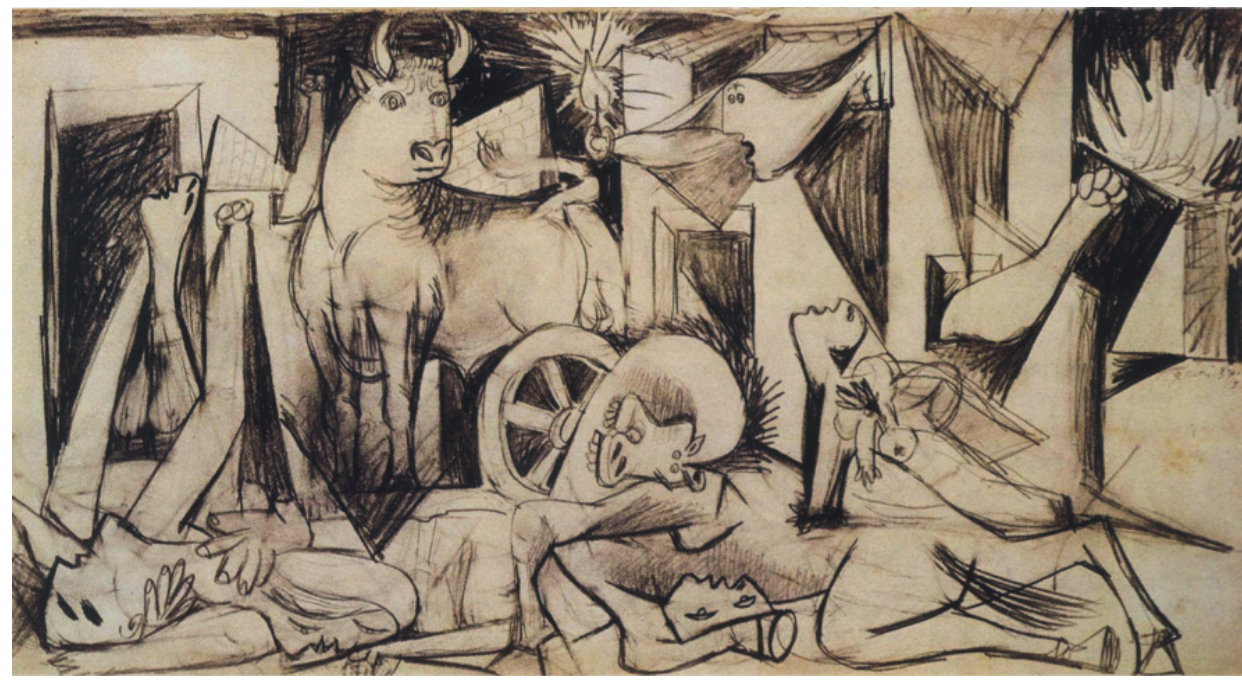

Fig. 6. Pablo Picasso. Boceto definitivo del Guernica. 1937. Museo Nacional Centro de Arte Reina Sofía, Madrid 
que en el contexto histórico en el que Picasso pintó el Guernica, continuaban teniendo una importante repercusión visual en las artes. Por un lado el genio de la libertad y por otro la alegoría de la libertad..$^{10}$

Para analizar la formación iconográfica del genio de la libertad, hay que recurrir a la Iconología de Cesare Ripa publicada en Roma en 1593. El autor incluye como ilustración para personificar el «crepúsculo de la mañana» a un joven alado desnudo que mira hacia el cielo, sobre su cabeza reposa una estrella y con su brazo derecho sostiene una antorcha. Ripa, con esta interpretación, no muestra a Eos, personificación femenina griega del amanecer, sino que personifica el propio concepto masculino del término crepúsculo. Del mismo modo muestra a Héspero, hijo de Eos y personificación griega de la tarde o «el crepúsculo de la tarde», como un joven alado que lanza con flechas los últimos rayos de la luz del día.

La obra de Cesare Ripa era bien conocida entre los ilustrados del siglo XVIII, esto lo demuestra, por ejemplo, el óleo sobre tela que pintó Antonio Rafael Mengs para personificar a Héspero en 1765, destinado a decorar el Palacio Real de Madrid junto a otros tres que representaban «el día», «la noche» y «la mañana». Mengs tomó como referencia directa para pintar esta obra la ilustración que Ripa incluyó en su Iconología para personificar «el crepúsculo de la tarde». Este efebo alado que plantea con antorcha o flechas sobre su mano y una estrella sobre su cabeza, aparecerá años más tarde en la portada de $L a$ Enciclopedia de 1751.

Los padres de La Enciclopedia, sin duda, quisieron ilustrar la portada de su gran obra con una alegoría que hiciese alusión a la luz que aporta la sabiduría para la libertad de la humanidad, el conocimiento que emerge desde las tinieblas de siglos de oscurantismo. En definitiva, una alegoría que personificase el amanecer de la cultura. Esta tarea le fue encomendada al grabador francés JeanMichel Papillon, que a su vez participó con varios artículos en la redacción de La Enciclopedia. Papillon diseñó este grabado en 1747, cuatro años antes de su publicación, y en 1766, volvió a emplear prácticamente el mismo diseño pero sustituyendo el efebo alado por otra alegoría en la portada de su Traité Historique et Practique de la Gravure en Bois publicado también en París.

Jean-Michel Papillon, en su condición de grabador e ilustrador, sin duda era conocedor de la Iconología de Cesare Ripa, obra a la que pudo recurrir en su cometido de diseñar una alegoría ex novo que personificase el amanecer de la cultura. Lo cierto es que el efebo alado que plantea para la portada de La Enciclopedia, guarda las mismas características que el de Ripa con la excepción de que ha sustituido la antorcha que lleva en su mano derecha por instrumentos que ayudan al ser humano a alcanzar la sabiduría. Papillon descubre a este «genio de la sabiduría» que emerge de entre los cielos como una estrella, el crepúsculo de la cultura que tiene como escabel todas las

10. NÉstor Morente y Martín: El art déco en la imagen alegórica de la in República española en València: Vicente Alfaro promotor de las artes, Tesis Doctoral Universitat de València, Valencia, 2017. 
ciencias y las artes que permiten a la humanidad alcanzar la verdad como única vía para lograr la verdadera libertad (fig. 7).

Este «genio de la sabiduría» que presentan los ilustrados en 1751, se metamorfoseará con la Revolución Francesa de 1789 en el «Genio de Francia» o el «Genio protector de la nación», símbolo que se hará muy popular y será difundido a partir de este momento. Su presencia no tardó en incorporarse entre la cultura visual de las artes producidas paralelas a la Revolución. Ejemplo de esto es la obra de Jean-BaptisteRegnault, El Genio de Francia entre la libertad o la muerte, que pintó en 1795. De igual modo aparecerá en gran parte de estampas del periodo revolucionario como uno de los protagonistas del nuevo imaginario simbólico y filosófico planteado para la nueva República francesa.

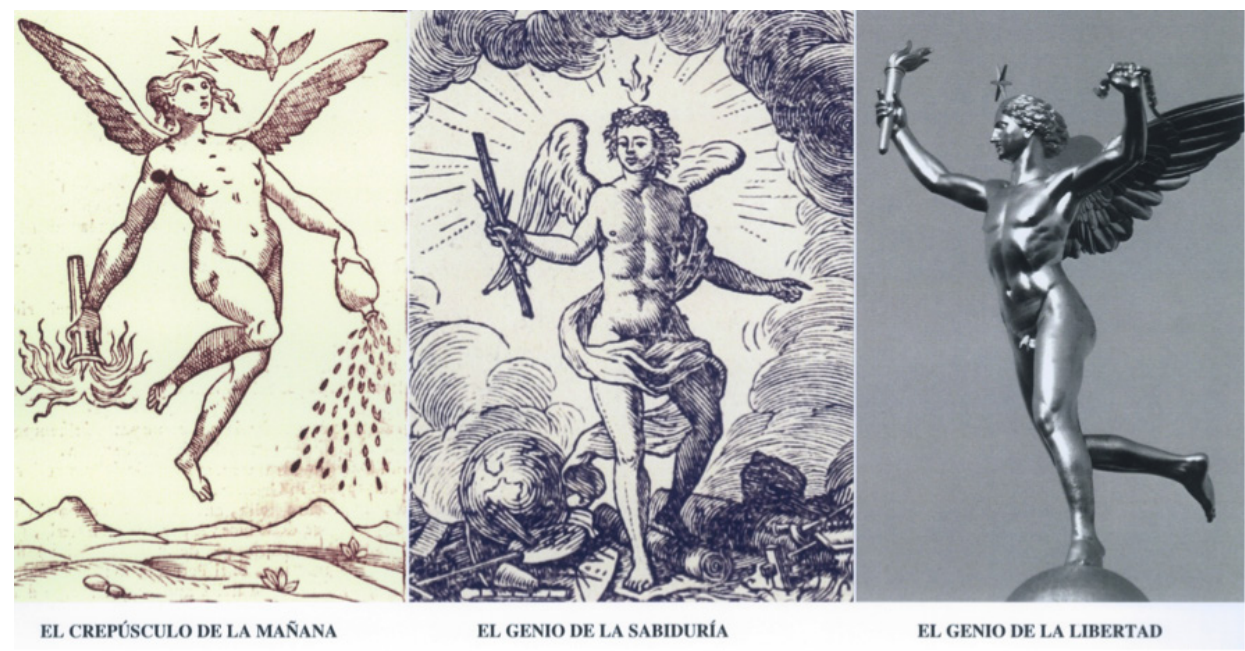

Fig. 7. Comparativa entre la Alegoría del CREPÚSCUlo de la mañanA de Cesare Ripa (1603), el genio de la sabiduría de La Enciclopedia (1747) y el Genio de la libertad de Auguste Dumont (1835)

$\mathrm{El}$ «Genio de Francia» no tardó mucho tiempo en presentar una nueva metamorfosis para convertirse en el definitivo genio de la libertad, este, al igual que «el crepúsculo de la mañana» de Cesare Ripa, volverá a portar la antorcha con su mano derecha. El modelo por excelencia de esta personificación de la libertad se encuentra coronando la Columna de Julio en la Plaza de la Bastilla de París. Se trata de una escultura colosal que realizó en bronce dorado Auguste Dumónt en 1835. Desde entonces, el genio de la libertad se difundió por todos los países europeos e iberoamericanos, que en sus nacientes repúblicas adoptaron también esta personificación como símbolo.

A mediados del siglo xIx, esta iconografía surgida ex novo de la Ilustración estaba totalmente formalizada entre la cultura visual de los pueblos -incluso monárquicos-, tal es el ejemplo español del Genio Catalán que realizó el es- 
cultor Fausto Baratta en 1856. El genio tendrá la función de sujetar la antorcha para iluminar a la República con la libertad, pero también el que releve la antorcha a la República para que ésta ilumine a su pueblo por el sendero de la verdad, de la razón y de la libertad. Esta cuestión hará que en muchas interpretaciones artísticas se representen juntos al genio de la libertad y la alegoría de la República, pues el genio ilumina a través del fuego de la verdad a la República y esta a su pueblo con la libertad. ${ }^{11}$

Cuando Picasso pintó el Guernica en 1937, esta iconografía estaba más que presente en la cultura visual de su tiempo, pues tanto en las exposiciones universales como en los Juegos Olímpicos y otros muchos eventos que se habían celebrado desde el siglo XIX, tanto el genio de la libertad como la alegoría de la República, eran los temas más representativos en carteles, medallas y otros soportes artísticos. Picasso, sin duda, era conocedor de esta iconografía tan desarrollada por las artes, y al tratarse de una Exposición Internacional, motivo más que justificado para tenerla en cuenta. Así pues, es más lógico pensar que la figura femenina que presenta con el quinqué sea más bien la alegoría de la República que la diosa Venus.

Para esta cuestión, procede analizar la otra alegoría contemporánea a Picasso que también tenía la antorcha como principal atributo, la alegoría de la libertad. Para tal fin también es necesario recurrir a la Iconología de Cesare Ripa, concretamente a la ilustración que plantea para personificar a la verdad. Ripa la presenta como una mujer desnuda y sobre su mano derecha muestra la figura del sol. Esta interpretación de la verdad fue el modelo a seguir ya en las artes del siglo XVII, lo ejemplifica la escultura en mármol -de casi tres metros de alturaque hizo Gian Lorenzo Bernini en 1645 con el título La Verdad descubierta por el Tiempo ubicada en la Galería Borghese de Roma.

Bernini, al igual que Ripa, presenta la Verdad al desnudo apoyando el sol sobre su mano derecha y colocando un pie sobre el Orbe. Con la Revolución Francesa, esta iconografía continuará, aunque para adaptarla a las circunstancias del momento. En el mensaje ilustrado de la Revolución, del que surgirá la alegoría de la República -creada ex novo- se creó todo un aparato iconográfico, filosófico y religioso para dar a conocer la verdad, la cual conduce a la razón y esta a la libertad, o dicho de otro modo, la verdad nos hará libres pero tan solo por medio de la razón.

La razón como único medio que conduce a la libertad desde la verdad, llegó incluso a convertirse en el nuevo culto religioso para los ilustrados de la Revolución francesa. El culto a la razón, instaló su templo en la catedral de NotreDame de París en 1793, la nueva diosa presentaba como principal atributo la antorcha de la verdad y la acompañaba otra imagen femenina, la libertad que vestía la tricolor francesa.

11. Carlos Reyero: Alegoría, nación y libertad. El Olimpo constitucional de 1812, Siglo XXI, Madrid, pp. 127-129. 
Por lo tanto, los ilustrados de la Revolución, tomaron como referencia la verdad de Ripa -concretamente el atributo del sol- trasladándola a la nueva alegoría de la razón. Es aquí cuando el sol de Ripa se metamorfosea en la antorcha que porta la razón y de ahí que también se simbolice, en definitiva, a la libertad con la «antorcha de la razón» que custodia la «luz de la verdad». ${ }^{2}$

Este sol-antorcha se representará también en algunas imágenes de la Revolución a modo de espejo, el genio de la libertad y la alegoría de la libertadRepública serán los que lo muestren para dar a conocer la verdad a través de la razón. Esta cuestión se ejemplifica en un grabado de 1793 que conserva la Biblioteca Nacional de Francia titulado El Tiempo descubre la Verdad que es sostenida por la Libertad y pisotea el feudalismo. Esta estampa es de interés pues presenta prácticamente la misma composición que Picasso empleó para el Guernica en lo que respecta al Sol y a la figura femenina que porta el quinqué (fig. 8).

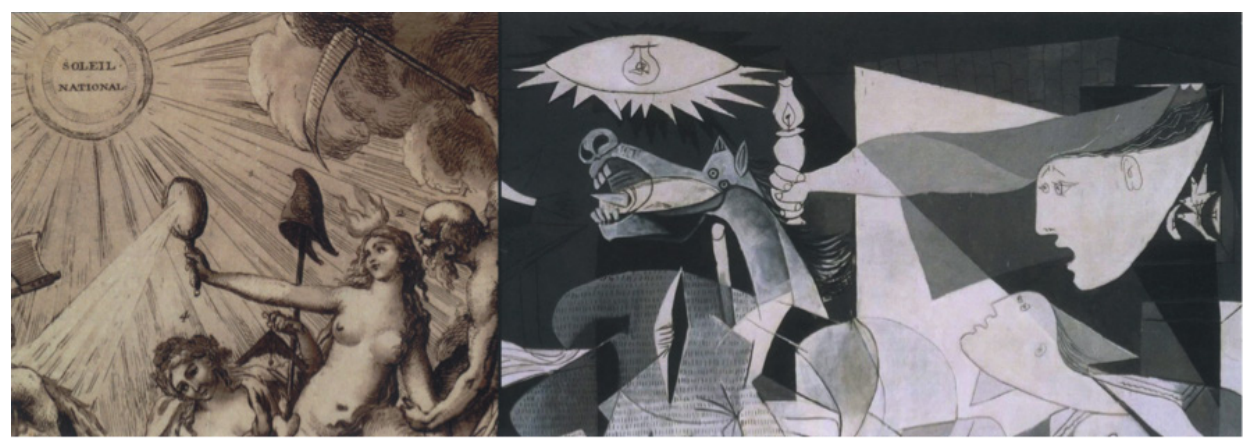

Fig. 8. Comparativa entre el detalle de la estampa titulada El tiempo descubre la Verdad... de 1793 y la alegoría con el quinqué del Guernica de Picasso, 1937

Toda esta compleja iconografía con la que experimenta la Revolución francesa para materializar en cierta manera todo el nuevo mensaje político y filosófico, concluyó en la definitiva formación de la alegoría de la República como personificación de la nación. Esta alegoría se verá representada en muy variados modelos y más aún cuando se extiende a los demás países, que irán proclamando sus respectivas repúblicas. Uno de estos modelos es la alegoría de la República portando la antorcha de la libertad, que en muchos casos es sostenida por el propio genio de la libertad, como es el ejemplo del monumento el Triunfo de la República, escultura de Aime-Jules Dalou, y que se encuentra en la Plaza de la Nación de París desde 1899.

La alegoría de la República portando la antorcha es por lo tanto una conciliación de tres conceptos que anteriormente habían sido personificados de forma independiente: la verdad, la razón y la libertad. Esta fórmula fue una

12. Fernando Prieto: La Revolución Francesa, Ediciones Istmo, Madrid, 1989. 
de las más divulgadas para personificar a la República, sin duda el ejemplo más conocido y espectacular por sus características es la escultura colosal de Nueva York que hizo Bartholdi, La libertad iluminando al mundo inaugurada en 1886. También España, cuando seproclamó la II República en 1931, adoptó como una de las variantes personificaciones republicanas la que porta la antorcha de la libertad (fig. 9 y 10).

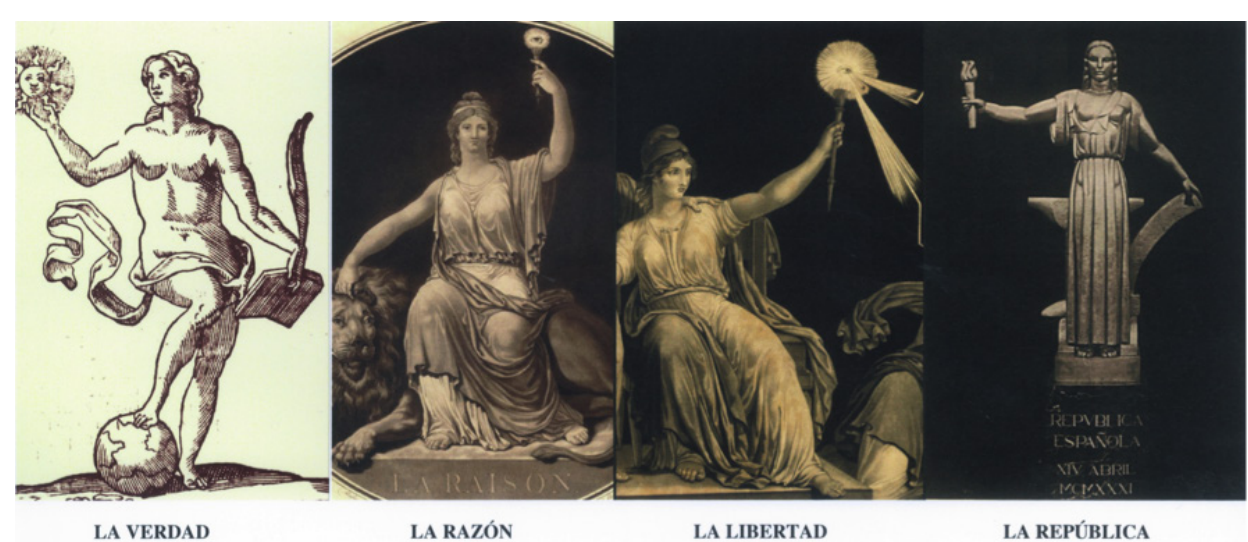

Fig. 9. Comparativa ente la Alegoría de la verdad de Cesare Ripa, 1603, con La Razón y la Libertad, estampas francesas del siglo XVIII y la Alegoría de la II República Española de Vicente Beltrán Grimal de 1932

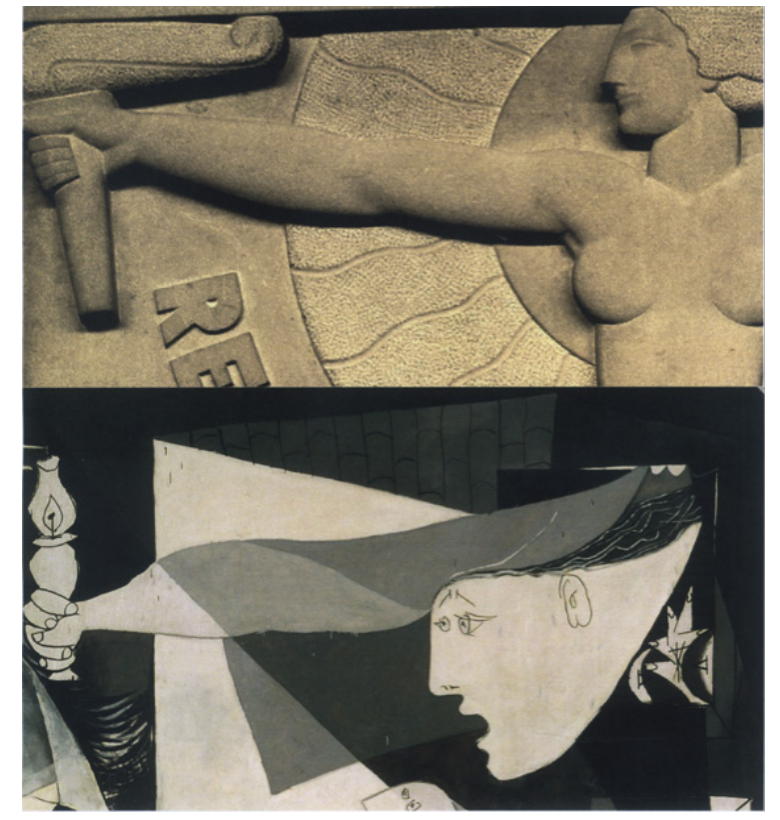

Fig. 10. Comparativa entre los detalles de la Alegoría de la II República Española de Ricardo Boix de 1932 y de Pablo Picasso del Guernica 1937 
Los dos ejemplos valencianos más destacados son las esculturas que realizaron los artistas Vicente Beltrán Grimal y Ricardo Boix, ambos en 1932, y en el mismo estilo art déco. En el caso de Beltrán Grimal -uno de los principales introductores de esta tendencia en el ámbito valenciano- en una escultura de madera en bulto redondo y con dimensión colosal destinada a presidir el Salón de Sesiones del Ayuntamiento de la capital del Turia. Más sencillo, sin embargo, aunque no por ello con menos calidad artística, el bajorrelieve realizado por Boix, sin duda el máximo exponente escultórico del art déco del País Valenciano.

Todos estos factores plantean la posibilidad de que Pablo Picasso incluyese en su obra como motivo central la antorcha de la libertad, sostenida en este caso por la alegoría de la II República Española, que se muestra al desnudo porque en ella reside la verdad. La República sale al encuentro de su pueblo para ahuyentar con el fuego de la libertad la amenaza del fascismo. Sin duda, Picasso representó en esta figura la personificación de la nación y el símbolo de la libertad en un momento en el que la alegoría republicana era un elemento de actualidad, prueba de ello es el propio cartel de Jean Carlú para anunciar la Exposición Internacional de París.

A modo de conclusión, cabe mencionar otras dos obras valencianas que se hicieron también en 1937 y que son, junto al Guernica de Picasso, el escaso ejemplo del arte republicano que ha llegado hasta nosotros como denuncia a la barbarie de la Guerra Civil y ambas hechas ex profeso para que se expusieran también en el pabellón español de la Exposición Internacional de París. En primer lugar, La Piedad, óleo sobre lienzo de Alfredo Claros en un estilo próximo al realismo socialista, muestra el dolor de una mujer que presencia la caída de su marido abatido en combate. Escena que sin duda toma como referencia $L a$ Piedad de Miguel Ángel y que de forma muy similar también incluye Picasso en el extremo izquierdo del Guernica, en la figura de la mujer que sostiene entre sus brazos a su hijo muerto. ${ }^{13}$

Y en segundo lugar, la escultura realizada por Ricardo Boix titulada Songez a la Douleurd'Espagne ('Pensad en el dolor de España'). En esta obra el escultor presenta una original composición en la que la mano de una madre aterrorizada protege a su hijo. Tema que también se relaciona con la escena del Guernica.

Quizás en el Guernica de Picasso se presenta uno de los últimos ejemplos en el que el repertorio artístico y visual de la Ilustración así como de la Revolución francesa en relación con los conceptos de verdad y libertad, se hace presente con una intencionalidad necesaria en la realidad contextual del momento. Al mismo tiempo, la obra traslada y plasma unos valores que se ilustran en una

13. Rafa Company: «Las complejidades de la modernidad en el arte figurativo: Valencia de una dictadura a otra», en La Modernitat Republicana a València. Innovacions i Pervivències en l'ArtFiguratiu (19281942), Valencia, 2016, pp. 35-40. 
perspectiva de la última vanguardia artística, composición que aún hoy refleja su propia modernidad y frescura.

Picasso nos dejó, en definitiva, una obra excepcional que muestra la atrocidad de la guerra civil española, pero también los desastres que pueden suceder, de ahí que siempre sea, además de por su singular composición, una obra presente y futura. No obstante, dejó un mensaje cargado de esperanza: la libertad sostenida por la república, una de las últimas representaciones de la alegoría de la II República Española y sin duda la más original, y aunque sigue despertando distintas interpretaciones entre los historiadores, lo cierto es que su luz sigue iluminando después de ocho décadas aquello que jamás debe volver a ocurrir (fig. 11).

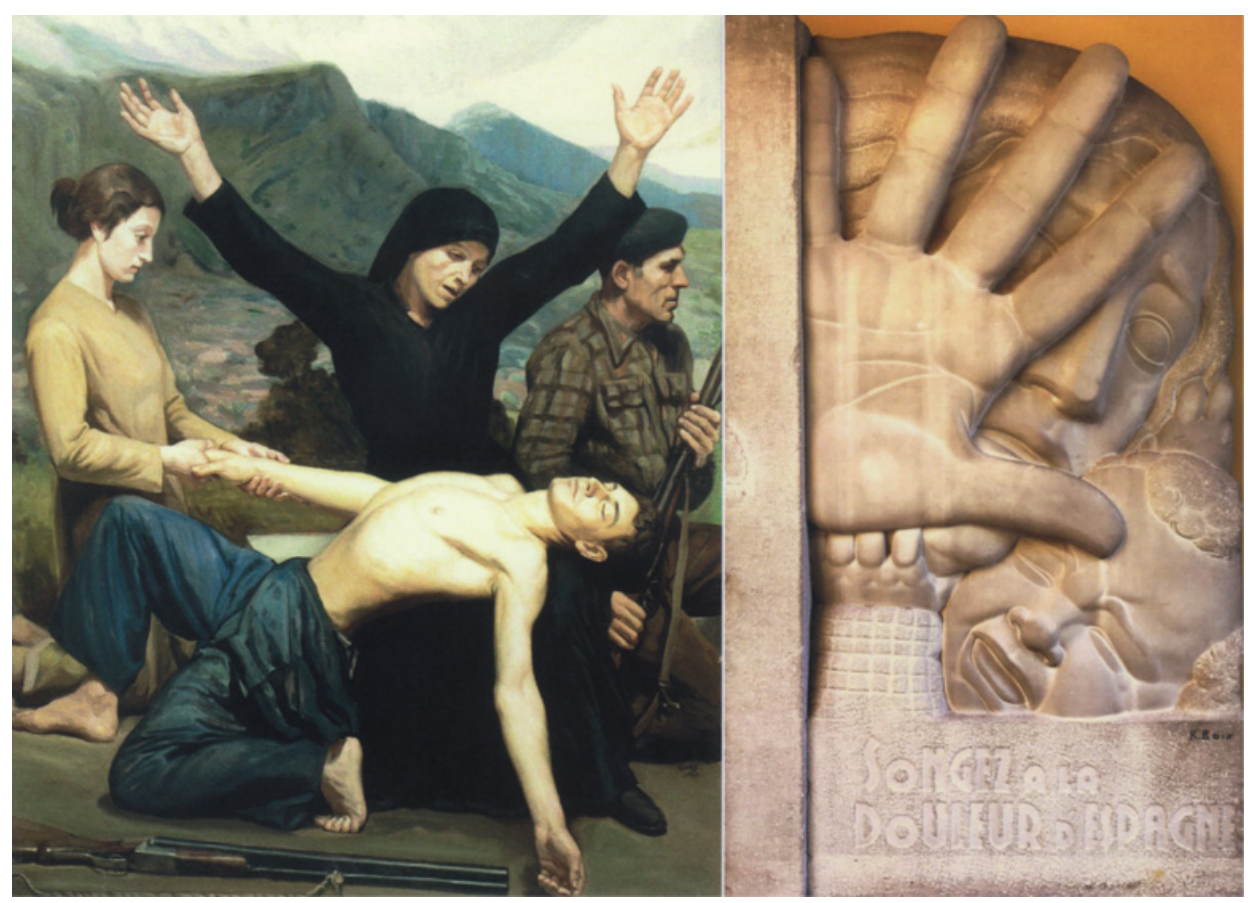

Fig. 11. La Piedad de Alfredo Claros, colección de Cristina Pons Claros y Songez a la douleur d`Espagne de Ricardo Boix, Museo de la Ciudad, Valencia, 1937 


\section{Bibliografía}

Alix Trueba, Josefina: Pabellón Español Exposición Internacional de París 1937, Centro de Arte Reina Sofía, Madrid, 1987.

COMPANY, RAFA: «Las complejidades de la modernidad en el arte figurativo: Valencia de una dictadura a otra», en La Modernitat Republicana a València. Innovacions i Pervivències en l'ArtFiguratiu (1928-1942), Valencia, 2016.

Fontes De Garnica, Ignacio: 1937: el crimen fue en Guernica. Análisis de una mentira, Akal, Madrid, 2014.

Larrea, Juan: Guernica: Pablo Picasso, Edicusa, Barcelona, 1977.

Morente y Martín, Néstor: El Art Déco en la imagen alegórica de la II República española en València: Vicente Alfaro promotor de las artes, Tesis Doctoral Universitat de València, València, 2017.

Prieto, Fernando: La Revolución Francesa, Ediciones Istmo, Madrid, 1989.

Reyero, Carlos: Alegoría, nación y libertad. El Olimpo constitucional de 1812, Siglo XXI, Madrid, 2010.

Sebastián, Santiago: El «Guernica» y otras obras de Picasso: contextos iconográficos, Departamento de Historia del Arte-Universidad de Murcia, Murcia, 1984.

Tusell, Genoveva: El Guernica recobrado. Picasso, el franquismo y la llegada de la obra a España, Cátedra, Madrid, 2017.

Vv. AA.: València, capital cultural de la República [1936-1937], Manuel Aznar Soler, Valencia, 2007, pp. 21-69.

Van Hensbergen, Gijs: Guernica: la historia de un icono del siglo XX, Debate, Madrid, 2005. 